\title{
Comparison of macroscopic abnormalities in patients receiving routine pantoprazole when compared to placebo
}

\author{
MJ Summers ${ }^{*}$, SP Selvanderan², MP Plummer ${ }^{1,2}$, ME Finnis ${ }^{1}$, Y Ali Abdelhamid ${ }^{1}$, MB Anderson ${ }^{1}$, MJ Chapman ${ }^{1,2}$, \\ CK Rayner ${ }^{3,4}$, AM Deane $e^{1,2}$
}

From ESICM LIVES 2015

Berlin, Germany. 3-7 October 2015

\section{Introduction}

Gastrointestinal (GI) mucosal abnormalities have been observed within $24 \mathrm{~h}$ of admission to ICU and are thought to represent a 'stress' response. While acid-suppressive drugs are frequently administered to ICU patients, for stress ulcer prophylaxis, there are sparse data to support its efficacy.

\section{Objectives}

To compare the presence of macroscopic mucosal abnormalities during upper GI endoscopy in mechanically ventilated, critically ill patients randomised to receive pantoprazole or placebo.

\section{Methods}

Ten patients were evaluated $(6 \mathrm{M}: 4 \mathrm{~F}$; age $41.7 \pm 4.3 \mathrm{y}$; admission APACHE II score $19.4 \pm 1.9$; pantoprazole $\mathrm{n}=4$, and placebo $\mathrm{n}=6$ ) from a larger prospective study, in which 209 mechanically ventilated patients were randomised to receive IV pantoprazole $(40 \mathrm{mg})$ or placebo in a double-blind fashion. Patients who received $\geq 5$ doses of pantoprazole/placebo (80 patients in total) were eligible for the endoscopy sub-study. Written and informed consent was obtained from the patient's next of kin. The presence of one or more macroscopic abnormalities (erythema or oedema, erosions, ulcerations and naso-gastric tube lesions) and GI bleeding (petechial or sub-mucosal bleeding, haematoma, coffeeground material and frank blood) were assessed at endoscopy by a single experienced gastroenterologist who was blinded to the intervention. Data are mean \pm SEM

${ }^{1}$ Royal Adelaide Hospital, Intensive Care Unit, Adelaide, Australia

Full list of author information is available at the end of the article or median (IQR) and were compared using Mann-Whitney $\mathrm{U}$ tests or chi-squared tests as appropriate.

\section{Results}

Patients had received pantoprazole $8.8 \pm 0.3$ doses or placebo $10.7 \pm 1.1$ doses prior to endoscopy $(p=0.21)$. One patient in the pantoprazole group was also receiving corticosteroids, and another received regular non-steroidal anti-inflammatory drug therapy. Patient's haemoglobin on the day of endoscopy were similar (pantoprazole: $89.8 \pm 6.0$ vs. placebo: $83.7 \pm 3.7 \mathrm{~g} / \mathrm{dL} ; \mathrm{p}=0.52$ ), one patient (receiving pantoprazole) had received a blood transfusion prior to endoscopy. All patients were receiving enteral nutrition prior to endoscopy. Upper GI mucosal abnormalities were observed in a total of 3 patients treated with pantoprazole $(75 \%)$ and 4 patients treated with placebo $(66 \%)$, without a difference between treatments $(\mathrm{p}=0.78)$. Observed abnormalities included

(i) erythema/oedema/erosions (pantoprazole: 2 patients vs. placebo: 2 patients)

(ii) naso-gastric tube-related lesions (3 vs. 2),

(iii) petechial or sub-mucosal bleeding ( 0 vs. 2$)$, and (iv) duodenal ulcer, (0 vs. 1); the latter was not associated with bleeding but the patient was switched to open label pantoprazole.

\section{Conclusions}

Upper GI mucosal abnormalities may occur frequently in mechanically ventilated patients. However, in this small cohort, the prevalence of mucosal abnormalities does not appear to be substantially reduced by administration of prophylactic pantoprazole. 


\section{Grant Acknowledgment}

This project was funded by a Royal Adelaide Hospital Research Foundation project grant.

\section{Authors' details}

${ }^{1}$ Royal Adelaide Hospital, Intensive Care Unit, Adelaide, Australia. ${ }^{2}$ The

University of Adelaide, Discipline of Acute Care Medicine, Adelaide, Australia.

${ }^{3}$ The University of Adelaide, Discipline of Medicine, Adelaide, Australia. ${ }^{4}$ Royal Adelaide Hospital, Department of Gastroenterology and Hepatology,

Adelaide, Australia.

Published: 1 October 2015

doi:10.1186/2197-425X-3-S1-A980

Cite this article as: Summers et al: Comparison of macroscopic

abnormalities in patients receiving routine pantoprazole when

compared to placebo. Intensive Care Medicine Experimental 2015

3(Suppl 1):A980.

\section{Submit your manuscript to a SpringerOpen ${ }^{\mathcal{O}}$ journal and benefit from:}

- Convenient online submission

- Rigorous peer review

- Immediate publication on acceptance

- Open access: articles freely available online

- High visibility within the field

- Retaining the copyright to your article

Submit your next manuscript at $\boldsymbol{s p r i n g e r o p e n . c o m ~}$ 